\title{
The implementation of inclusive education in the Kabardino-Balkarian Republic under the conditions of digitalization
}

\author{
Olga Mikhailenko*, Zhansurat Bashiyeva, Fatimat Balkizova, Budimir Nagoev \\ Kabardino-Balkarian State University named after H.M. Berbekov, 340004, Nalchik, Russia
}

\begin{abstract}
The article considers the use of informational technologies in the implementation of inclusive education. Based on legal acts, we substantiated the creation of special conditions for children with disabilities in the school educational environment. During the analysis of the reality of implementing inclusive education, the leading directions are identified; a cluster model for the development of inclusive education using information technologies is described. The main advantage of the social and academic direction of the implementation of inclusive education is the creation of conditions for maximum self-actualization and selfrealization of children with disabilities. The study results indicate the need to prepare society and the educational environment for the quality improvement of life of children with disabilities.
\end{abstract}

\section{Introduction}

In modern times, a child with disabilities is considered an active subject of the surrounding society, where conditions for his maximum possible self-realization and integration into society are created. The normative documents that provide the legal basis for education note, that children with developmental problems have the same rights as everyone else.

In this regard, ensuring the availability of quality education, individualization, and differentiation, as well as conditions for achieving a new modern quality of general education, is one of the main directions of education modernization. The purpose of this study was to identify the features of the implementation of inclusive education in the context of digitalization.

Inclusive education is interpreted in the law "On Education in the Russian Federation" as ensuring equal access to education for all students, taking into account the diversity of special educational needs and personal opportunities.

The law "On Education in the Russian Federation" states that the realization of every person's right to education, the necessary conditions quality education by people with disabilities must be created, for correcting developmental disorders and social adaptation, providing early correctional assistance, as well as social development of these individuals [13]. This provision of the law is implemented through the introduction of inclusive education.

\footnotetext{
* Corresponding author: olganlk@mail.ru
} 
Inclusive education (fr. Inclusif - including, lat. In-clude - I conclude, include, involve) is one of the processes of transformation of general education, based on the understanding that people with disabilities in modern society can (and should) be involved in society. This transformation focuses on the creation of conditions for the accessibility of education for all, including providing access to education for children with disabilities. Public Efforts in the 1990s - 2000s and the formation of public opinion made it possible to start creating conditions for this type of pedagogy, which received the name inclusive (involving) [10, 374].

The works of S.V. Alekhinoy, M.A. Alekseeva, M.M. Bezrukikh, E.L. Goncharova, O. I. Kukushkina, N.N. Malofeeva, N. Ya. Semago, L.M. Shipitsina, N.D. Shmatkoy etc. shows the issues of inclusive education. As N.Ya. Semago rightly notes, inclusion is a deep process, which, along with technologies and methods of development, training, and development of children with disabilities, also includes a special model of their perception and position in society [11, p.2].

Among the main directions of the development of inclusive education are the use of information technologies and the development of distance learning to ensure equal access for everyone to receive a quality education; training of teaching staff to work in inclusive education $[5,3]$.

The introduction of information and communication technologies is a response to the need of modern society for mass and continuous education, to improve its quality level in connection with the increased requirements for the consumer and producer of material and spiritual benefits $[15,14]$.

Unfortunately, there are significant problems in the use of new information technologies in the educational process, caused by the following factors: the lack of an information technology infrastructure, software, and hardware, optimized based on the use of technologies intended for children with disabilities. To date, distance learning for disabled children is considered one of the most important innovations of modern schools in the Russian Federation [12, 211].

We agree with the opinion of S.V. Alekhina that education, focused on the principles of inclusion, changes social relations towards accepting differences, prioritizes support and cooperation, changes and adapts the conditions and environments for development and satisfying the educational goals of each student $[9,8]$.

Inclusive education makes it possible to realize educational goals not only for students with developmental disabilities but also for children who, to one degree or another differ from the general group of children [2, 222].

The inclusive practice involves the life quality improvement of a special child and their family, without deteriorating life quality of other participants in the educational process, presupposes the creation of the necessary conditions for achieving success in social adaptation and education by all children without exception, regardless of their characteristics, educational achievements, language, culture, their mental and physical capabilities $[11,2]$. An important role is played by computer training, which allows them to choose "the optimal distance in relations with people with disabilities and create a psychologically safe virtual environment for them, in which they can establish their boundaries and achieve greater independence" [7].

The State Program "Development of Education" for 2013-2020 of 15.05.2013 No. 792-r reflects the need to implement programs to ensure high-quality preschool, school, and additional education for children and people with disabilities, including measures to create a barrier-free learning environment, develop infrastructure and technologies for distance learning for children with disabilities, models of inclusive education, psychological, medical and social support for vocational guidance, dissemination in all constituent entities of the Russian Federation, the practice of developing inclusive schools [4]. 
In this regard, the education system of the Kabardino-Balkarian republic joined the international project "Development of social inclusion of children with disabilities in the republics of the North Caucasus." The main goal of this project is the improvement of the social support systems for children and their parents in the North Caucasus region, owing to the support of public organizations. In educational institutions of Kabardino-Balkaria, some positive experience in teaching children with disabilities within the framework of inclusion has been accumulated. The social program "Accessible Environment" has been fully completed in prior educational institutions, where children with disabilities and healthy children are educated together. To ensure the access of a child with disabilities to an educational institution, the entrance to school buildings was modified with a ramp; special equipment for children with hearing, vision, speech, and musculoskeletal disorders has been installed. Schools are supplied with equipment that ensures the comfortable existence of children with disabilities in the conditions of general schools. Favorable conditions for children with disabilities are created by the presence in educational institutions of a dry pool, treadmills, exercise bicycles, there is a willingness to carry out educational and treatment-and-prophylactic measures. Special attention is paid, along with the creation of the material and technical base, the organization, and the content of the educational process.

The use of information technologies in the organization of persons with disabilities lies in the possibility of providing multimedia of computer teaching aids allowing the activation of compensatory mechanisms of students based on preserved types of perception, taking into account the principle of a polysensory approach and overcoming developmental disorders.

Multimedia presentation of objects and processes through photos, videos, graphics, animation, and sound rather than traditional textual descriptions. Students find the novelty of the multimedia lessons interesting.

The use of digital educational resources helps teachers to significantly reduce the time for presenting the material, create appealing teaching and didactic manuals, handout assessment and testing materials necessary for the implementation of the assigned correctional educational tasks, quickly find basic and additional educational materials on the topic of the lesson.

\section{Materials and methods}

We studied school documents in educational institutions that implement inclusive education to identify the issues and prospects for the development of inclusive education; a survey was carried out among teachers of schools of the republic and parents of students.

The analysis of the adaptive educational programs, plans, correctional programs with developmental orientation, also as consultative and diagnostic orientation, educational work, individual development maps of students, suggests that inclusive education in schools of the republic is conducted in two directions: socio-academic and socio-personal.

The survey covered 180 people: 60 parents of children with disabilities, 80 parents of healthy children, 40 teachers. The main parameters of the study were parents' awareness of inclusive education; the attitude of parents to joint education of children with disabilities and their healthy peers; parents' expectations related to the introduction of inclusive education; the need for children with disabilities in educational services; informational and methodological provision of teachers; difficulties experienced by teachers in the implementation of inclusion.

The respondents' answers indicate that the republic population is not fully aware of the value of inclusive education, which justifies the need for large-scale work, including the media efforts, to form an inclusive culture in the society.

The primary and important condition for the development of inclusive practice, 
according to domestic researchers (E.L. Agafonova, M.N. Alekseeva, S.M.Dmitrieva, E.N. Kutepova, N.N. Malofeev, N.M. Nazarova, N. Ya. Semago, IM Yakovleva, etc.) is the training of competent teachers who are capable and ready to work effectively with children with disabilities.

The teacher's professional willingness for inclusive practice in the educational environment is the level of his knowledge and professionalism, which allows him to make optimal decisions in a specific pedagogical situation. Three special competence groups represent it: organizational and managerial, educational, and methodological $[3,89]$.

A.K. Markova notes that in the partial training process of the teachers' professional competence should build namely: professional (objectively necessary) pedagogical knowledge (gnostic component); professional-pedagogical positions, teacher attitudes required in his profession (value-semantic component); professional (objectively necessary) pedagogical skills (activity component); personal characteristics that ensure the mastering of professional knowledge and skills by the teacher (personal component) [8, 59].

In relation to the inclusive practice implementation in educational institutions, we decided to study the level of willingness of primary school teachers for inclusive education. The study was carried out in general education schools and special (correctional) schools of the Kabardino-Balkarian Republic (KBR). The study involved 58 teachers.

To determine the level of teachers' willingness to form an inclusive educational environment in general education organizations, we suggested that teachers fill out the "Self-assessment questionnaire of teachers' readiness to form an inclusive educational environment" by O.V. Karynbaeva. Teachers needed to assess their willingness for each indicator. We identify each of the three components of willingness identified (motivationalpersonal, cognitive, social-legal) represented by distinct professional competencies.

\section{Results}

The results indicate that the level of willingness for inclusive education in terms of the motivational and personal component is optimal and amounts to $62 \%$.

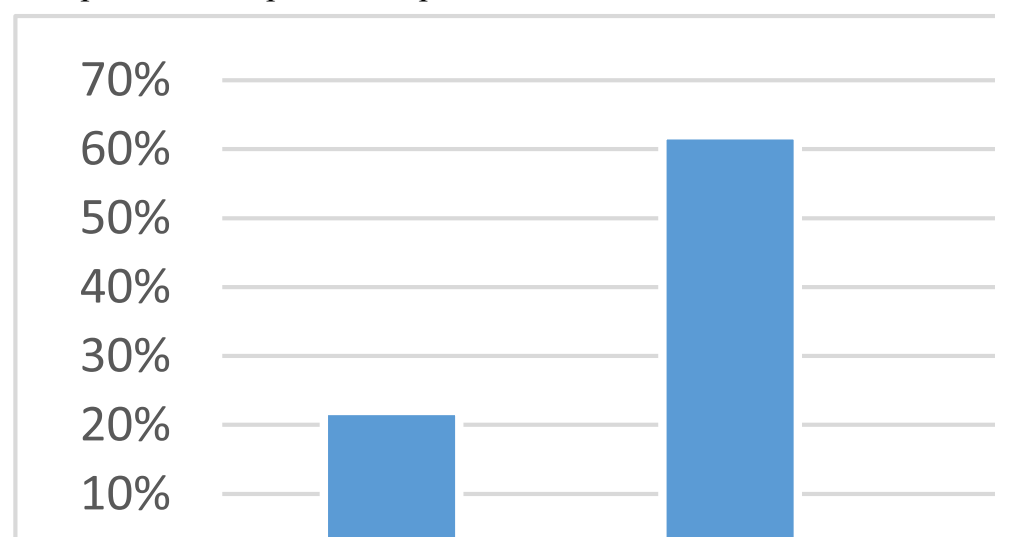

Fig. 1. Diagram of the level of readiness of teachers to implement inclusive education

This shows that the majority of teachers are ready to provide assistance and a tolerant attitude towards children with disabilities, realize the importance of working with them, show pedagogical optimism, exercise self-control, and self-regulation, but feel the need for professional and pedagogical improvement, in cooperation. With scientific consultants, difficulties in showing empathy for children with disabilities, note the need for professional training in the use of ICT in inclusive education. 
The analysis of the research results showed that the motivational and personal component of teachers of general education schools is at a high level, the social and legal component is at an average level, and the cognitive component is at a low level. The majority of teachers, at the optimal level, noted difficulties in using information technologies in inclusive education, while they present new opportunities for teaching people with disabilities.

\section{Discussion}

In this regard, we believe that the creation of an inclusive education center that ensures the coordination of the work of teachers of special (correctional) educational institutions, teachers of mass educational institutions, specialists of different levels and qualifications, parents, students will contribute to more effective implementation of inclusive learning practices. The staff of the Institute of Pedagogy, Psychology and Physical Culture and Sports Education of the Kabardino-Balkarian University (KBSU) has developed a cluster model for inclusive education development. In our opinion, the cluster model for the development of inclusive education for people with disabilities and persons with disabilities presupposes a way of interaction between institutes, faculties, other structural units of the university, and educational institutions of the republic as a whole, which carry out inclusive education. The core of this cluster will be the Center for Inclusive Education, the coordinating activity of which is effective implementation will possibly subject to the cooperation of educational organizations (Kindergarten - School - SPE - University). When creating a continuous educational vertical, these institutions can implement in practice a systematic approach to the problem of including children with special educational needs in society. This approach is possible by organizing a team of specialists and teachers of each educational institution, who are ready to work in a unified manner of integrative education with the active use of digital technologies.

We agree with the opinion of M.P. Karpenko, it is important to organize computertraining centers in higher educational institutions, equipped with the necessary equipment $[6,63]$. To implement effective cooperation, it is necessary to operate a distance learning system, equip educational institutions with a complex of technical means, conduct training on the use of technical means and electronic resources for teachers and students, as well as rework educational and methodological complexes, taking into account the peculiarities of distance

learning.

The introduction of distance learning for certain categories of children with disabilities as an innovative technology has revealed several advantages: access of disabled children to educational and other information resources; socialization and integration of children with disabilities into society; wide coverage of the audience of students; taking into account the individual attributes of children; interactivity of training; spatial and temporal infinity of learning; continuous technological improvement; high-quality education of children with disabilities; support for families of disabled children.

The structure of the cluster model of a continuous inclusive educational space illustrates the close interaction of educational institutions, based on the active use of information technologies, from a preschool education institution to a higher education institution, with the cooperation of organizations that provide further professional activities. The subjects of the inclusive educational vertical are students with special educational needs, their parents, as well as the teaching and tutoring staff of educational institutions.

The described cluster model lies on several principles for the construction of inclusive education, including the principles of the supremacy of socialization, individualization, integrativeness of pedagogical support of subjects, the principle of tolerance, and value 
attitude towards the subjects of the integrative structure of a continuous inclusive educational space.

Taking into account the emerging need for training personnel engaged in inclusive education, the staff of the Department of Pedagogical Education has developed an innovative program "Actual Problems of Inclusive Education Using Information and Communication Technologies", the purpose of which is to provide comprehensive fundamental training of highly qualified education specialists, capable of designing innovative development of inclusive education systems in secondary and higher education, as well as capable of independent research, teaching, and practical activities.

Without questioning the importance of students' organized practice, we propose, among other things, the inclusion of the experience of unregulated activities in the educational process of forming competencies. Volunteer practice can play this role in the preparation of a teacher.

The volunteer movement of students under the programs of social and socio-cultural rehabilitation of disabled children, peers with disabilities, and people with disabilities started at the Institute of Pedagogy, Psychology, Physical Culture and Sports Education in September 2017. Volunteer students provide tutoring support for children with disabilities, according to the established schedule,

To select applicants for volunteers, we surveyed first, second and third-year students of the Institute of Teachers, Psychology and Physical Culture and Sports Education.

All students who took part in the survey emphasize a benevolent attitude towards students with various physical disabilities.

The educational program for volunteers involves the active use of information technology. As part of the educational program for volunteers, training seminars are held. Also, a campaign has been prepared for the International Day of the Disabled. Social media platforms were used to publish articles on the work progress and inform people about the project implementation stages.

\section{Conclusions}

Therefore, a step-by-step motion towards a modern education model, which provides students with disabilities equal access to the newest information technologies, will allow them to purposefully form the possibilities of choosing educational resources, to provide an unprecedented variability of educational trajectories. The implementation of the possibilities of modern information technologies expands the range of educational activity types allowing the enhancement of existing organizational forms, creation of new ones, and improvement of teaching methods. It gives a reason for the formation of a barrier-free educational environment in which equal rights and opportunities to receive quality education will be provided.

\section{References}

1. N.V. Alyokhina, M.N. Alekseeva, E.L. Agafonova, Psychological science and Education 1, 85 (2011).

2. B.N. Bubeeva, Bulletin of the Buryat State University 1, 221-225 (2010).

3. D.V. Vorobyova, The concept of psychological and professional readiness of teachers in working with children with disabilities in inclusive practice, a collection of articles based on the materials of the X International Scientific and Practical Conference. Part I, Novosibirsk, SibAK, 2011. 
4. The state program of the Russian Federation "Development of education for 2013-2020 years from 15.05.2013 No. 792-r" [Electronic resource]

5. Inclusive education: problems of improving the educational policy and system, Mat. mezhdunar. konf. 19-20 June 2008-St. Petersburg: Publishing House of the Herzen State Pedagogical University, 2008.

6. M.P. Karpenko, Sociological research 3, 63-68 (2007).

7. A.I. Kopytin, Art therapy in secondary school. Methodological guide (Academy of Postgraduate Pedagogical Education, St. Petersburg, 2005).

8. O.S. Kuzmina, Preparation of teachers for work in the conditions of inclusive education, diss. for the degree of Candidate of Pedagogical Sciences, Omsk, 2015.

9. A.S. Pugachev, A young scientist 10, 374-377 (2012).

10. N.Ya. Semago, Autism and developmental disorders 4, 1-9 (2010).

11. L.I. Tuybaeva, Scientific and methodological electronic Journal "Concept" 37, 211-215 (2015). URL: http://e-koncept.ru/2015/95665.htm.

12. Federal Law No. 273-FZ of 29.12.2012 (as amended on 02.03.2016) " On Education in the Russian Federation "[Electronic resource]

13. A.V. Khutorsky, The concept of distance learning, Distance and virtual learning: Digest of the Russian and foreign press 4, (SSU, Moscow, 1999).

14. E.A. Shchannikova, E.V. Saraeva, Scientific and Methodological electronic Journal "Concept" 32, 233-237 (2016). URL: http://e-koncept.ru/2016/56691.htm. 